\title{
Analisis Pengaruh Penggunaan Mesin Peniris Gorengan Terhadap Kualitas Gorengan
}

\author{
B. Budiana*, Fenda Alang Darmansyah, Rahmi Mahdaliza, Fitriyanti Nakul, dan Irwanto \\ Zarma Putra
}

Teknik Elektro, Politeknik Negeri Batam, Batam, Indonesia

*Email: budiana@polibatam.ac.id

\begin{abstract}
Abstrak-Minyak goreng yang tersimpan dalam jumlah banyak pada gorengan akan meningkatkan risiko masalah kesehatan sehingga diperlukan teknik untuk mengeluarkan minyak goreng yang berlebihan pada gorengan. Teknik yang dapat dilakukan adalah dengan menggunakan penirisan manual dan dengan menggunakan mesin peniris otomatis. Penggunaan dua teknik tersebut akan dianalisis melalui penelitian ini. Metode yang digunakan pada penelitian ini terdiri atas persiapan gorengan yang akan digunakan, persiapan peniris gorengan, pengujian sistem dan penimbangan massa gorengan. Dengan membandingkan bakwan, tahu dan tempe, diperoleh kesimpulan bahwa jenis gorengan yang memiliki persentase penurunan massa tertinggi dimiliki oleh gorengan bakwan dengan nilai persentase sekitar $10 \%$. Jenis kecepatan mesin high speed memberikan persentase penurunan massa paling tinggi untuk semua jenis kecepatan dengan nilai persentase penurunan massa sekitar $10 \%$. Setelah proses penirisan, semua jenis gorengan memiliki kualitas yang baik karena tidak mengalami kerusakan, baik berupa sobek, patah, maupun pecah.
\end{abstract}

Kata kunci: Gorengan, penirisan, machine

\section{LATAR BELAKANG}

GORENGAN merupakan salah satu jenis makanan yang digemari oleh masyarakat. Namun, konsumsi gorengan yang berlebihan dapat meningkatkan risiko masalah kesehatan (contohnya penyakit jantung dan diabetes) [1][2]. Peningkatan risiko masalah kesehatan pada gorengan diakibatkan oleh penggunaan minyak goreng yang digunakan secara berulangulang. Selain dari itu, minyak goreng yang digunakan tersimpan dalam jumlah banyak pada gorengan [3].

Solusi yang sudah diterapkan terhadap minyak goreng yang tersimpan pada gorengan adalah melalui penirisan manual. Solusi ini tentunya tidak efektif karena memerlukan waktu yang relatif lama. Waktu yang relatif lama ini disebabkan karena tidak adanya pengaruh dari luar untuk menekan minyak keluar dari gorengan. Solusi lain yang telah diterapkan adalah menggunakan alat penirisan gorengan. Alat penirisan gorengan telah dikembangkan oleh berbagai peneliti untuk berbagai jenis gorengan [4][5][6][7][8][9]. Namun, penggunaan alat peniris gorengan tentunya memerlukan biaya tambahan terutama untuk para pedagang gorengan yang terbiasa menggunakan cara manual untuk meniriskan minyak pada gorengan. Dengan demikian, perlu dilakukan kajian atas penggunaan mesin peniris otomatis tersebut. Pada jurnal ini, peneliti tidak berfokus pada pembuatan alat yang digunakan untuk peniris gorengan, melainkan pada analisis pengaruh penggunaan mesin peniris gorengan terhadap kualitas gorengan (bakwan, tahu dan tempe) setelah proses penirisan. Kualitas gorengan mengacu pada tekstur dari gorengan sebelum dan sesudah dilakukan penirisan.

\section{METODE PENELITIAN}

\section{A. Persiapan Gorengan}

Penelitian ini menggunakan tiga jenis gorengan yaitu bakwan, tempe dan tahu. Pemilihan tiga jenis gorengan ini berdasarkan pada tekstur gorengan yang cenderung mudah mengalami kerusakan ketika diberikan pengaruh dari luar. Massa dari masing-masing gorengan dikukur sebelum dan sesudah ditiriskan. Tujuan adanya penimbangan ini adalah untuk melihat perbandingan massa gorengan sebelum dan sesudah penirisan.

\section{B. Persiapan Mesin Peniris Gorengan}

Mesin yang digunakan untuk peniris gorengan terlihat seperti pada Gambar 1.

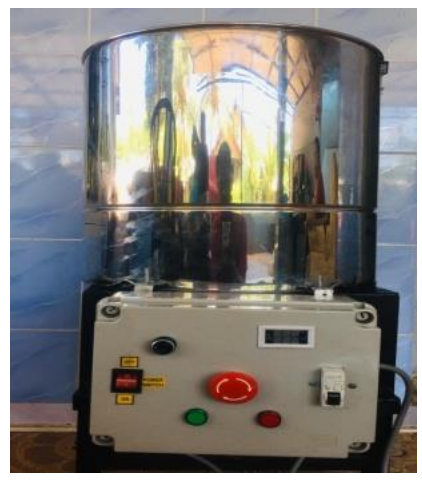

Gambar 1. Mesin yang digunakan untuk penirisan gorengan (bakwan, tahu dan tempe) 


\section{Pengujian Sistem}

Pengujian ketiga jenis gorengan dibagi menjadi dua teknik, yaitu penirisan secara manual (tanpa menggunakan mesin) dan penirisan dengan menggunakan mesin peniris. Mesin peniris yang digunakan memiliki tiga variasi kecepatan yaitu high speed, middle speed dan low speed. Perbedaan nilai Rotation per Minute (RPM) untuk masing-masing jenis variasi kecepatan disajikan pada Tabel I.

TABEL I

VARIASI KECEPATAN YANG DIGUNAKAN PADA ALAT PENIRIS GORENGAN

\begin{tabular}{clc}
\hline No & $\begin{array}{c}\text { Jenis Variasi } \\
\text { kecepatan }\end{array}$ & RPM \\
\hline 1 & High Speed & 960.6 \\
2 & Middle Speed & 827.1 \\
3 & Low Speed & 724.9 \\
\hline
\end{tabular}

\section{Penimbangan Massa Gorengan}

Gorengan sebelum ditiriskan dan sesudah ditiriskan ditimbang massanya. Tujuan dilakukan penimbangan ini adalah untuk mengetahui selisih atau persentase pengurangan massa untuk setiap jenis gorengan yang digunakan.

\section{HASIL DAN ANALISIS}

\section{A. Hasil pengujian Bakwan}

Kualitas dari bakwan ditentukan dari tekstur/permukaan bakwan yang telah mengalami proses penirisan. Kualitas bakwan dikatakan baik jika setelah proses penirisan tidak terjadi sobekan pada seluruh bagian bakwan atau sebagian bakwan (lihat Tabel II).

TABEL II

\begin{tabular}{cccc} 
DATA GORENGAN BAKWAN & SEBELUM DAN SESUDAH PROSES PENIRISAN \\
\hline \hline $\begin{array}{c}\text { Jenis } \\
\text { Penirisan }\end{array}$ & $\begin{array}{c}\text { Jenis } \\
\text { kecepatan }\end{array}$ & $\begin{array}{c}\text { Gambar } \\
\text { Sebelum }\end{array}$ & $\begin{array}{c}\text { Gambar } \\
\text { Sesudah }\end{array}$ \\
\hline Manual & - & & \\
\hline
\end{tabular}

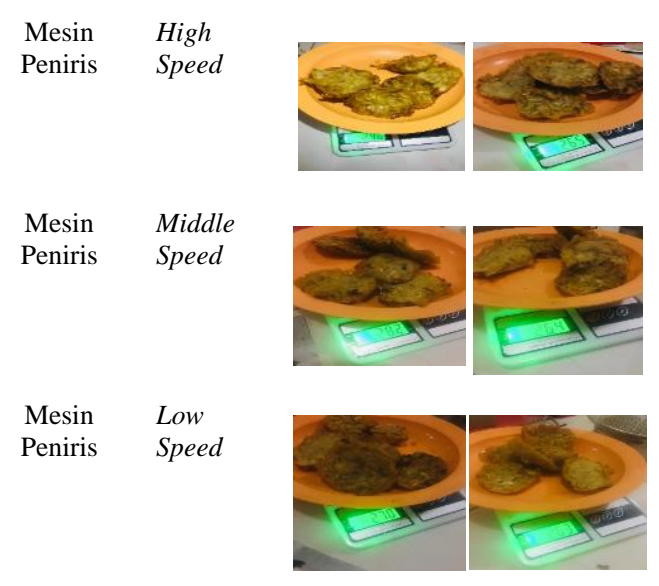

Berdasarkan Tabel II terlihat bahwa gorengan bakwan tidak mengalami perubahan bentuk dan tidak mengalami sobekan di seluruh atau sebagian bakwan sehingga bakwan yang telah mengalami proses penirisan memiliki kualitas baik.

Kuantitas dari bakwan ditentukan dengan melakukan perhitungan massa dari gorengan bakwan. Gorengan bakwan yang digunakan sebelum penirisan ditimbang massanya sebelum dan sesudah penirisan. Hasil percobaan ditunjukan pada Tabel III.

TABEL III

DATA GORENGAN BAKWAN SEBELUM DAN SESUDAH PROSES PENIRISAN

\begin{tabular}{clccc}
\hline \hline $\begin{array}{c}\text { Jenis } \\
\text { Penirisan }\end{array}$ & $\begin{array}{c}\text { Jenis } \\
\text { kecepatan }\end{array}$ & $\begin{array}{c}\text { Massa } \\
\text { Sebelum } \\
\text { (gram) }\end{array}$ & $\begin{array}{c}\text { Massa } \\
\text { Sesudah } \\
\text { (gram) }\end{array}$ & $\begin{array}{c}\text { Selisih } \\
\text { (gram) }\end{array}$ \\
\hline $\begin{array}{c}\text { Manual } \\
\text { Mesin }\end{array}$ & $\begin{array}{l}\text { High } \\
\text { Speed }\end{array}$ & 296 & 295 & 1 \\
$\begin{array}{c}\text { Peniris } \\
\text { Mesin }\end{array}$ & $\begin{array}{l}\text { Middle } \\
\text { Speed } \\
\text { Peniris } \\
\text { Mesin }\end{array}$ & 282 & 265 & 30 \\
Peniris & Speed & 270 & 263 & 17 \\
\hline
\end{tabular}

Jenis penirisan yang paling tinggi menurunkan massa bakwan adalah jenis penirisan dengan menggunakan mesin peniris yang memiliki kecepatan high speed. Sedangkan jenis penirisan yang paling rendah menurunkan massa gorengan bakwan adalah penirisan manual. Penirisan manual memiliki nilai paling rendah disebabkan karena tidak adanya energi yang diberikan pada gorengan bakwan untuk melakukan kerja pada bakwan untuk mengeluarkan minyak yang tersimpan.

\section{B. Hasil pengujian Tempe}

TABEL IV

\begin{tabular}{|c|c|c|c|}
\hline $\begin{array}{c}\text { Jenis } \\
\text { Penirisan }\end{array}$ & $\begin{array}{c}\text { Jenis } \\
\text { kecepatan }\end{array}$ & $\begin{array}{l}\text { Gambar } \\
\text { Sebelum }\end{array}$ & $\begin{array}{l}\text { Gambar } \\
\text { Sesudah }\end{array}$ \\
\hline Manual & - & & \\
\hline
\end{tabular}

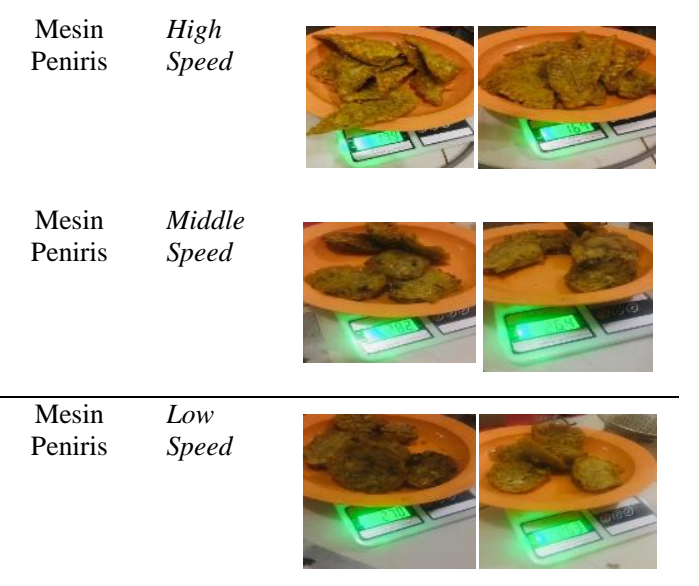

Kualitas dari gorengan tempe ditentukan berdasarkan tekstur/permukaan gorengan tempe yang telah mengalami 
proses penirisan. Kulitas gorengan tempe dikatakan baik jika seteleh proses penirisan tidak terjadi patahan/sobekan pada seluruh atau sebagian gorengan tempe (Tinjau Tabel IV).

Berdasarkan Tabel IV terlihat bahwa gorengan tempe tidak mengalami perubahan bentuk/sobekan/patah diseluruh atau sebagian tempe. Sehingga gorengan tempe yang telah mengalami proses penirisan memiliki kualitas baik. Perhitungan massa dari gorengan tempe sebelum dan sesudah penirisan ditunjukan pada Tabel V.

Jenis penirisan yang paling tinggi menurunkan massa gorengan tempe adalah jenis penirisan dengan menggunakan mesin peniris yang memiliki kecepatan high speed. Sedangkan jenis penirisan yang paling rendah menurunkan massa tempe adalah menggunakan penirisan manual.

TABEL V.

\begin{tabular}{clccc} 
DATA GORENGAN TEMPE SEBELUM DAN SESUDAH PROSES PENIRISAN \\
\hline \hline $\begin{array}{c}\text { Jenis } \\
\text { Penirisan }\end{array}$ & $\begin{array}{c}\text { Jenis } \\
\text { kecepatan }\end{array}$ & $\begin{array}{c}\text { Massa } \\
\text { Sebelum } \\
\text { (gram) }\end{array}$ & $\begin{array}{c}\text { Massa } \\
\text { Sesudah } \\
\text { (gram) }\end{array}$ & $\begin{array}{c}\text { Selisih } \\
\text { (gram) }\end{array}$ \\
\hline Manual & - & 180 & 179 & 1 \\
Mesin & High & 179 & 164 & 15 \\
$\begin{array}{c}\text { Peniris } \\
\text { Mesin }\end{array}$ & $\begin{array}{l}\text { Speed } \\
\text { Middle }\end{array}$ & 168 & 163 & 5 \\
$\begin{array}{c}\text { Peniris } \\
\text { Mesin }\end{array}$ & $\begin{array}{l}\text { Speed } \\
\text { Low }\end{array}$ & 161 & 158 & 3 \\
Peniris & Speed & & &
\end{tabular}

\section{Hasil pengujian Tahu}

TABEL VI.

DATA GORENGAN TAHU SEBELUM DAN SESUDAH PROSES PENIRISAN

\begin{tabular}{|c|c|c|c|}
\hline $\begin{array}{c}\text { Jenis } \\
\text { Penirisan }\end{array}$ & $\begin{array}{c}\text { Jenis } \\
\text { kecepatan }\end{array}$ & $\begin{array}{l}\text { Gambar } \\
\text { Sebelum }\end{array}$ & $\begin{array}{l}\text { Gambar } \\
\text { Sesudah }\end{array}$ \\
\hline Manual & - & & \\
\hline $\begin{array}{l}\text { Mesin } \\
\text { Peniris }\end{array}$ & $\begin{array}{l}\text { High } \\
\text { Speed }\end{array}$ & & \\
\hline $\begin{array}{l}\text { Mesin } \\
\text { Peniris }\end{array}$ & $\begin{array}{l}\text { Middle } \\
\text { Speed }\end{array}$ & & \\
\hline $\begin{array}{l}\text { Mesin } \\
\text { Peniris }\end{array}$ & $\begin{array}{l}\text { Low } \\
\text { Speed }\end{array}$ & & \\
\hline
\end{tabular}

Penentuan kulitas gorengan tahu pada dasarnya sama dengan penentuan kualitas dari gorengan bakwan dan tempe. Identifikasi penentuan kualitas gorengan tahu berdasarkan adanya sebokan/patahan/hancuran setelah proses penirisan. Tabel VI menyajikan gambar dari gorengan tahu sebelum dan sesudah proses penirisan.
Perhitungan massa dari gorengan tahu. ditunjukan pada Tabel VII. Berdasarkan Tabel VII terlihat bahwa gorengan tahu mengalami penurunan massa yang cukup tinggi jika menggunakan jenis variasi kecepatan high speed. Penggunaan kecepatan high speed memungkinkan energi yang diberikan pada tahu juga tinggi sehingga energi yang diberikan tersebut digunakan untuk mengeluarkan minyak yang tersimpan pada tahu.

TABEL VII.

\begin{tabular}{clccc} 
DATA GORENGAN TAHU SEBELUM DAN SESUDAH PROSES PENIRISAN \\
\hline \hline No & $\begin{array}{c}\text { Jenis Variasi } \\
\text { kecepatan }\end{array}$ & $\begin{array}{c}\text { Massa } \\
\text { Sebelum } \\
\text { (gram) }\end{array}$ & $\begin{array}{c}\text { Massa } \\
\text { Sesudah } \\
\text { (gram) }\end{array}$ & $\begin{array}{c}\text { Selisih } \\
\text { (gram) }\end{array}$ \\
\hline 1 & Manual & 146 & 146 & 0 \\
2 & High Speed & 146 & 136 & 10 \\
3 & Middle Speed & 136 & 130 & 6 \\
4 & Low Speed & 130 & 127 & 3 \\
\hline
\end{tabular}

Hubungan antara semua jenis gorengan dengan persentase massa dan jenis penirisan dapat dilihat pada Gambar 2. Jika dilihat berdasarkan Gambar 2, terlihat bahwa persentase kehilangan massa tertinggi berada pada jenis gorengan bakwan. Hal ini terjadi karena tekstur dan ketebalan bakwan sendiri yang cenderung lebih padat dan lebih tebal jika dibandingkan dengan gorengan tempe dan tahu sehingga kemampuan menyerap dan mengeluarkan minyak paling tinggi jika dibandingkan dengan jenis gorengan lainnya.

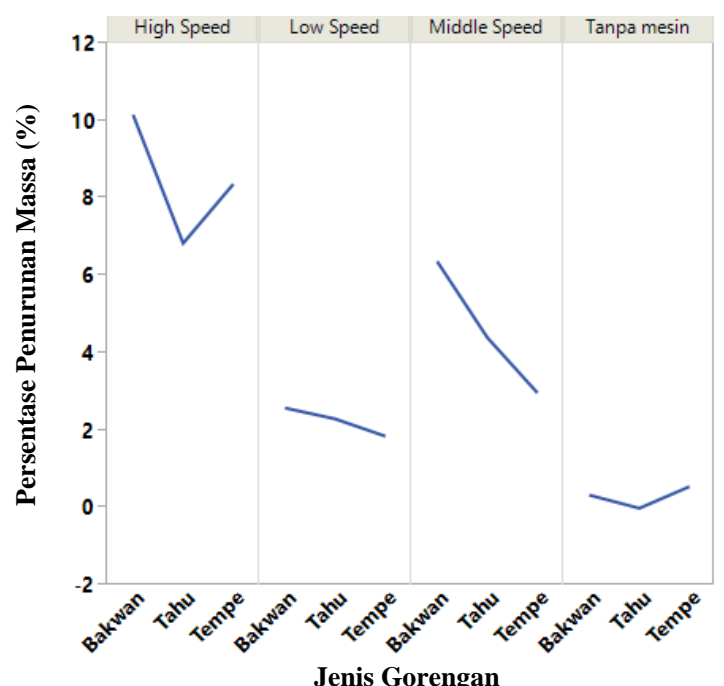

Gambar 2. Perbandingan persentase penurunan massa untuk seluruh jenis gorengan dan variasi kecepatan mesin.

\section{KESIMPULAN}

Jenis gorengan yang memiliki persentase penurunan massa tertinggi dimiliki oleh gorengan bakwan dengan nilai persentase sekitar $10 \%$. Jenis kecepatan mesin high speed memberikan persentase penurunan massa paling tinggi untuk semua jenis kecepatan dengan nilai persentase penurunan massa sekitar $10 \%$. Semua jenis gorengan setelah mengalami proses penirisan dengan semua jenis tipe penirisan tidak mengalami kerusakan berupa sobekan/patahan/pecah sehingga kualitas dari semua jenis gorengan tetap baik. 


\section{REFERENCES}

[1] S. D. Ardhany and L. Lamsiyah, "Tingkat Pengetahuan Pedagang Warung Tenda di Jalan Yos Sudarso Palangkaraya tentang Bahaya Penggunaan Minyak Jelantah bagi Kesehatan," J. Surya Med., vol. 3, no. 2, pp. 62-68, Feb. 2018, doi: 10.33084/jsm.v3i2.99.

[2] I. M. B. Ilmi, "Kualitas Minyak Goreng dan Produk Gorengan selama Penggorengan di Rumah Tangga Indonesia," J. Apl. Teknol. Pangan, vol. 04, no. 02, 2015, doi: 10.17728/jatp.2015.12.

[3] Y. Hanum, "DAMPAK BAHAYA MAKANAN GORENGAN BAGI JANTUNG," J. Kel. SEHAT Sejah., vol. 14, no. 2, Art. no. 2, Dec. 2016, doi: $10.24114 / \mathrm{jkss} . v 14 \mathrm{i} 28.4700$.

[4] W. Luo, B. Lu, H. Zheng, Y. Guo, and T. Huang, "A research of spinning machine: Effect of different structures of feed system on the static and dynamic characteristics," Adv. Mech. Eng., vol. 11, p. 168781401982845 , Feb. 2019, doi: 10.1177/1687814019828451.

[5] M. Adriana and R. Syahyuniar, "RANCANG BANGUN ALAT PENIRIS MINYAK PADA KERIPIK SINGKONG," Elem. J. Tek. MESIN, vol. 6, p. 20, Jun. 2019, doi: 10.34128/je.v6i1.90.

[6] A. Thoriq, T. Herwanto, and D. Ciptaningtyas, "MODIFIKASI MESIN PENIRIS MINYAK DAN KELAYAKAN FINANSIAL PRODUKSI KERIPIK BAYAM," J. Tek. Pertan. Lampung J. Agric. Eng., vol. 7, p. 63, Aug. 2018, doi: 10.23960/jtep-l.v7i2.63-71.

[7] S. Wasisto, I. L. I. Purnama, and P. W. Anggoro, "PERANCANGAN MESIN PENIRIS UNTUK ANEKA MAKANAN RINGAN HASIL GORENGAN," p. 9, 2016.

[8] W. K. Sugandi, A. M. Kramadibrata, F. Fetriyuna, and Y. Prabowo, "Analisis Teknik dan Uji Kinerja Mesin Peniris Minyak (Spinner) (Technical Analysis and Test Performance of Oil Spinner Machine)," $J$. Ilm. Rekayasa Pertan. Dan Biosist., vol. 6, no. 1, pp. 17-26, Mar. 2018, doi: 10.29303/jrpb.v6i1.65.

[9] I. Irdam, D. Setiawan, A. Irmayanti, and A. Aditya, "Rancang Bangun Mesin Peniris Minyak,” Din. J. Ilm. Tek. Mesin, vol. 11, p. 77, May 2020, doi: 10.33772/djitm.v11i2.11799. 